OPEN ACCESS

Edited by:

Jisun Kim,

University of Ulsan, South Korea

Reviewed by:

Hyun Jo Youn

Chonbuk National University,

South Korea

Min Kyoon Kim

Chung-Ang University, South Korea

*Correspondence:

Ayşe Kayali Vatansever

aysekayali@outlook.com

TORCID:

Ayşe Kayali Vatansever orcid.org/0000-0001-9557-7918

Specialty section:

This article was submitted to

Women's Cancer,

a section of the journal

Frontiers in Oncology

Received: 30 September 2019

Accepted: 13 March 2020

Published: 12 May 2020

Citation:

Kayali Vatansever A, Yavuzșen $T$ and Karadibak D (2020) The Reliability and Validity of Quality of Life Questionnaire

Upper Limb Lymphedema (ULL-27)

Turkish Patient With Breast Cancer Related Lymphedema. Front. Oncol. 10:455.

doi: $10.3389 /$ fonc. 2020.00455

\section{The Reliability and Validity of Quality of Life Questionnaire Upper Limb Lymphedema (ULL-27) Turkish Patient With Breast Cancer Related Lymphedema}

\author{
Ayşe Kayali Vatansever ${ }^{1 \star x}$, Tuğba Yavuzşen ${ }^{2}$ and Didem Karadibak ${ }^{3}$ \\ ${ }^{1}$ Bayrakli District Health Directorate, Izmir, Turkey, ${ }^{2}$ Institute for Oncology, Dokuz Eylul University, Izmir, Turkey, ${ }^{3}$ Physiotherapy \\ and Rehabilitation, Dokuz Eylul University, Izmir, Turkey
}

Purpose: Breast cancer is the most common cancer amongst women both in Turkey and in the world. Lymphedema, which negatively affects the quality of life, is one of the most prevalent problems reported by breast cancer survivors. Upper Limb Lymphedama 27 (ULL-27) questionnaire is a valid and reliable tool that assesses the quality of life in patients with breast cancer-related lymphedema. Until now, a Turkish-language version was lacking. The aim of this study was to perform a cross-cultural validation and reliability of the Turkish version of the ULL-27 questionnaire.

Methods: This cross-sectional study involved forward- backward translation, and cross-cultural adaptation. 81 women (mean age and body mass index $54.96 \pm$ 11.35 years and $29.50 \pm 5.74 \mathrm{~kg} / \mathrm{m}^{2}$ ) who had breast cancer related-upper extremity lymphedema were evaluated using the ULL-27 Quality of life questionnaire-Turkish version. Assessment of limb size was quantified by using circumferential limb measurements. European Organization for Research and Treatment of Cancer (EORTC) 30-item Quality of Life Questionnaire and Quality of Life Questionnaire breast cancer-23 (QLQ-BR23) were analyzed by Pearson's correlation analysis with the ULL-27 Turkish Version to indicate the convergent validity. Cronbach's alpha (internal consistency) and exploratory factor analysis were used to assess the questionnaire's reliability.

Results: The mean of lymphedema duration and severity were $23.12 \pm 30.88$ months. Mild lymphedema was reported in 42\% (34 people) of the cases included in the study. It was observed that 33.3\% (27 people) had moderate lymphedema and 24.7\% (20 people) had severe lymphedema. The alpha coefficient (internal consistency) for the Turkish ULL-27 total score was high (alpha $=0.93$ ). Content validity was good because all questions were understandable for all participants (The alpha coefficient for the subgroups of the scale of physical, psychological, social scores, were 0.90, 0.87, and 0.75 , respectively). External construct validity was highly confirmed by expected correlations with comparator scales, EORTC-30, and QLQ-BR23 ( $p<0.01)$. 
Conclusions: The Turkish version of the ULL-27 Questionnaire is a valid and reliable tool for evaluating QoL in women with upper limb lymphedema related to breast cancer.

Keywords: ULL-27 quality of life questionnaire, breast cancer, lymphedema, quality of life, eortc30

\section{INTRODUCTION}

Breast cancer is still the most common type of cancer among women in the world (1). Its incidence rates have been increasing mostly in developing countries, including Turkey (2). But breast cancer survival rates have also increased worldwide. The recent decline in breast cancer mortality in many countries might be due to early diagnosis and improved treatment protocols $(3,4)$. Among the many symptoms, lymphedema is one of the most common side effects of breast cancer treatment.

A recent meta-analysis of women with breast cancer, the lymphedema rate was $21.4 \%$. The risk of developing lymphedema is especially high during the first two years of the surgery (5). Many sources indicate the likelihood of lymphedema development between 2 and 50\% (6-9). Lymphedema is a chronic and progressive condition resulting from an abnormality of, or damage to, the lymphatic system. Any reduction in the capacity of the lymphatic system to drain fluid from the interstitium and return it to the blood circulation will cause fluid to build up in the skin and subcutaneous tissues of the affected part of the body. It is known to negatively affect the quality of life (QoL) in breast cancer survivors due to limb swelling, heaviness, pain, pitting of skin, tightness or hardness in the limb, inflammation, and reduced mobility in the shoulder and arm (10-14).

There is a widespread awareness among researchers on the importance of assessing the specific quality of life related to lymphedema. On the other hand, very few specific questionnaires have been developed on upper extremity lymphedema. Upper Limb Lymphedema 27 (ULL-27), introduced by Launois et al. (15) is a scale that can describe all symptoms in one form, can provide a holistic approach, is easy to use, and can evaluate their ability to perform common functional activities in patients with Breast Cancer Related Lymphedema (BCRL). However, The ULL-27 has been validated in very few countries. Therefore, the aims of this study were: (1) to perform a translation and cross-cultural adaptation of the ULL-27 among patients with breast cancer related-upper extremity lymphedema, to investigate the scale's validity, and to conduct exploratory factor analysis (confirmatory factor analysis has been done previously in other languages) with responsiveness within a Turkish-speaking population sample; and (2) to assess quality of life in Turkish patients with breast cancer related-upper extremity lymphedema.

\section{MATERIALS AND METHODS \\ Study Design and Participants}

This study was performed on 81 women who had developed upper extremity lymphedema after breast cancer treatment. Participants who were referred to Dokuz Eylul University (DEU) Hospital, Department of Medical Oncology in Izmir, Turkey between June 2016 and May 2017 were assessed in the School of Physical Therapy. All participants were informed about the purpose and the procedures of the study and signed an informed consent form according to guidelines approved by the university hospital ethical committee. Ethical protocol number was 2543GOA and decision number was 2016/07-23.

To meet the inclusion criteria, patients had to: (a) be aged 18 and over; (b) have received no local and systemic treatment (colorectal surgery, chemotherapy, radiotherapy) in the last 6 months; (c) able to read, write, and understand Turkish; (d) have mild-moderate-severe degreed lymphedema; (e) be willing and able to attend the study. Women were ruled ineligible according to the following exclusion criteria: malignant lymphedema; recurrent cancer or infection in the arms; severe disorders related to cognition, muscles, or joints.

\section{Assessment}

A complete medical history was obtained from each participant, including demographic information (i.e., age, gender, height, weight, body mass index [BMI], occupation, dominant hand, and affected hand) and disease characteristics (i.e., type and side). In addition, the type of operation, the number of excised lymph nodes, radiotherapy session received, other treatments, lymphedema duration, and previous infection attacks were also recorded.

\section{Circumferential Measurement}

Edema was assessed by circumferential measurement (CM). $\mathrm{CM}$ were taken with participants in a supine position and the arm abducted at $30^{\circ} \mathrm{C}$. The circumference of both limbs was measured every $5 \mathrm{~cm}$, starting at the nail bottom of $3 \mathrm{rd}$ fingers and continuing $50 \mathrm{~cm}$ proximally. The difference between both arms were recorded in $\mathrm{cm}$. All patients were evaluated with the same standard tape measure $(150 \mathrm{~cm}$ length, $7 \mathrm{~mm}$ width). The severity of the edema was done according to the criteria set by the American Physical Therapy Association. According to this, the difference between both limbs is slightly less than $3 \mathrm{~cm}$, the middle $3-5 \mathrm{~cm}$, anything over $5 \mathrm{~cm}$ was recorded as severe lymphedema (16).

\section{Design}

This cross-sectional methodological study involved translation, back translation, and cross-cultural adaptation, that is, localization. To assess the questionnaire's reliability, Cronbach's alpha (for internal consistency) and exploratory factor analysis were conducted. To indicate the convergent validity, Pearson's correlation analysis was performed with the European Organization for Research and Treatment of Cancer Quality of Life Cancer module (EORTC QLQ-C30) and the European Organization for Research and Treatment of Cancer Quality 
of Life-Breast Cancer Module (EORTC BR-23) for which reliability and validity studies have been conducted in the Turkish-speaking population.

Women participating in the research were evaluated by the same researchers; information was given about the purpose and methods of the study. All measurements were carried out face to face with the participants. All evaluations lasted about 45-60 min.

\section{Quality of Life}

EORTC QLQ-C30, EORTC BR-23 and ULL-27 were used to measure QoL.

The EORTC QLQ-C30 is composed of 30 items assessing global perceived health status and QoL (QL2). These items are grouped into five functional scales (physical-PF2, role-RF2, cognitive-CF, emotional-EF, and social functioning-SF); three symptom scales (fatigue-FA, nausea \& vomiting-NV, and painFA); six single item scales-dyspnea-DY, insomnia-SL, appetite loss-AP, constipation-CO, diarrhea-DI, and financial difficultiesFI (17).

QLQ-BR23 has 23 items to assess functional scales (Body Image-BRBI, Sexual Functioning-BRSEF, Sexual EnjoymentBRSEE, and Future Perspective-BRFU); symptom scales (systemic therapy side effects -BRST, breast symptoms -BRBS, arm symptoms -BRAS, and upset by hair loss-BRHL) (17).

The QLQ scores vary from 0 (worst) to 100 (best) for the functional and global health status (GHS) parameters and from 0 (best) to 100 (worst) for symptoms parameters. A five-point difference in QoL scores is considered the minimum clinically significant difference. Both questionnaires were cross-culturally adapted to Turkish by Demirci et al. (18).

The original ULL-27 was created by Launois et al. (15). It is a questionnaire that evaluates the quality of life in three dimensions in subjects with upper limb lymphedema. The scale consists of 27 questions with physical, psychological, and social dimensions. 5-point Likert scoring scale $(1=$ strongly disagree, $5=$ strongly agree) is used. The first 15 questions are on the physical dimension (min 15 and $\max 75$ points), the questions between 16 and 22 on social dimension (min 7 and $\max 35$ points), and the questions between 23 and 27 evaluate the social dimension ( $\min 5$ and $\max 25$ points) of the individual. The total score of 27 questions is calculated for the global score. The lowest score is 27 and the highest score is 135 points. The high score of the scale shows that it affects the quality of life of the individual badly (15).

\section{Convergent Validity}

Convergent validity is the principle that measures theoretically similar constructs that should be highly intercorrelated. The convergent validity of two similar constructs can be estimated using correlation coefficients. To test the hypothesis for convergent validity for the ULL-27, we used the EORTC QLQ-C30, QLQ-BR23. Convergent validity in subjects with upper extremity lymphedema after breast cancer treatment was evaluated by investigating correlations between the scale's psychometric parameters and the commonly used assessments EORTC QLQ-C30, QLQ-BR23.

\section{Translational and Cross-Cultural Adaptation}

The process of translation and cross-cultural adaptation, that is, localization, was carried out according to Beaton's guidelines $(19,20)$.

(a) Translation into Turkish: the ULL-27 was translated from English into Turkish in accordance with Newmark's concept of "communicative translation" to achieve a dynamic equivalence between the source and target texts. "Communicative translation attempts to produce in its readers an effect as close as possible to that obtained on the readers of the original." The text was independently translated by two native Turkish speakers, one of whom was a linguist and the other a health care professional who knew English as a second language. Finally, both target texts were compared for equivalent effect, and a single version was agreed upon. (b) Back translation into English: two bilingual translators with English as a first language back translated the agreed Turkish version into English taking into account cultural adaptation, that is, the localization process. They compared the two versions and agreed on a single version. (c) Review committee: the final version was submitted to a bilingual committee consisting of clinicians and translators. The text was checked for semantic and idiomatic equivalence acceptable for dynamic equivalence. Step 3 ended with a final approval. (d) Test of the prefinal version: the prefinal version was sent to the authors of the original form, and their comments were taken into consideration. Then, the final version was piloted with 15 women by testing what was meant by each item and response chosen in order to verify whether the formulation of the item was clear or not. All of the findings were reevaluated by the expert committee. Finally, the back translation of the scale was approved by the author who composed the original form.

\section{Statistical Analysis}

Data analysis was made with Statistical Package for Social Science (SPSS) version 20. All categorical data frequency and percentage were calculated. Descriptive statistics on the demographics of patients were used to show information about cancer and lymphedema. Statistical significance level was regarded as 0.05 for all tests. Confirmatory factor analysis was used to test the construct validity of the questionnaire. In light of the assumptions set forth in the multiple regression analysis to examine a dependent variable, Path analysis was performed on all arguments. Quality of life survey to measure the reliability and Cronbach's alpha coefficients were calculated to measure the internal consistency. Cronbach's alpha was determined to be an acceptable level of reliability above 0.7. A poll of the Kolmogorov-Smirnov test to measure compliance that conforms to a normal distribution was made. Three major scores of the questionnaire (physical, psychological, and social) and the correlation between the content in question was examined by Spearman correlation test. ULL27 life-selected EORTC QLQ-C30 and QLQ-BR23 questionnaires quality of parallel survey evaluated concurrent validity by calculating the Pearson correlation. 


\section{Ethical Considerations}

The study was approved by the local University Medical Ethics Committee, and the patients gave their written informed consent to take part in the research prior to the study. R. Launois, the creator of the original ULL-27, was asked for permission to apply the scale in a convergent validity study for the Turkish language. In addition, during the ethical considerations, the Head of the Dokuz Eylul University Faculty of Medicine, Department of Oncology, approved the study to be held in their department.

\section{RESULTS}

Patients' compliance during evaluation was good. The EORTC30 and BR23 questionnaires were handed out to the patients and they were requested to fill in the forms. Eighty-one patients diagnosed BCRL with a mean age of $54.96 \pm 11.35$ years were enrolled in the study. Demographic and clinical data related to the patients are given in Table 1.

\section{Reliability of ULL-27 Questionnaire}

The reliability of the scale, internal consistency, and item scores were investigated in terms of correlation and invariance. ULL27 internal consistency of the quality of life questionnaire (reliability) was assessed by Cronbach's alpha score. Analysis of the internal consistency of all cases related to the scale of its response to the ULL-27 quality of life questionnaire was out of the total score. Croncbach alpha coefficient of 0.93 was found. Subgroups of the scale of physical scores had an alpha coefficient of 0.90 , psychological 0.87 , and social score 0.75 identified. Accordingly, the survey revealed that the degree of internal consistency was good. According to this model, when we look at the reliability analysis, all questions are consistent and valid for the Turkish people, without removing any items from the original survey (Table 2). Agent scale correlation (inter correlation) was rated on the same answer and substance-test are displayed by calculating the correlation coefficient. The obtained substance-test coefficients of correlation $r=0.43$ and $r=0.87$ was found to take values from Table 3. Test-retest analysis scale was determined by inter class correlation method. The test was applied twice to the last 15 patients at 20-day intervals. In both applications, the reliability coefficient taken according to the total scores was $r=0.40$ ( $p>0.05)$. Calculating a consistency coefficient, item-correlation coefficients and the number of testretest times were used to show statistical significance. These results scale internal consistency, substance-test shows that the correlation coefficient is high and test-retest reliability examined for the test.

\section{ULL-27 Validity of Questionnaire}

The validity of the ULL-27; parallel forms (concurrent) were analyzed in two ways: validity and construct validity. ULL27 was used in order to determine the construct validity of the questionnaire survey according to the applied confirmatory factor analysis. It was first seen in the value of RMSEA confirmatory factor analysis. The RMSEA value of our study was found to be 0.074 . According to the Path diagram, the first 15 questions were on the physical score in the Turkish version,
TABLE 1 | Demographic characteristics of the participants $(n=81)$.

\begin{tabular}{|c|c|}
\hline Age (years) $(X \pm S D)$ & $54.96 \pm 11.35$ \\
\hline $\mathrm{BMl}\left(\mathrm{kg} / \mathrm{m}^{2}\right)(X \pm \mathrm{SD})$ & $29.50 \pm 5.74$ \\
\hline Waist circumference $(\mathrm{cm})(X \pm S D)$ & $95.39 \pm 10.50$ \\
\hline Hip circumference $(\mathrm{cm})(X \pm S D)$ & $109.73 \pm 10.34$ \\
\hline \multicolumn{2}{|l|}{ Occupation (\%) } \\
\hline Housewife & 59.3 \\
\hline Worker & 24.7 \\
\hline Retired & 16 \\
\hline \multicolumn{2}{|l|}{ Dominant arm (\%) } \\
\hline Right & 92.6 \\
\hline Left & 7.4 \\
\hline \multicolumn{2}{|l|}{ Effected arm (\%) } \\
\hline Right & 43.2 \\
\hline Left & 56.8 \\
\hline \multicolumn{2}{|l|}{ First observed part of lymphedema in arm (\%) } \\
\hline Hand & 21 \\
\hline Forearm & 19.8 \\
\hline Upper arm & 29.6 \\
\hline \multicolumn{2}{|l|}{ Severity of lymphedema (\%) } \\
\hline Mild & 42 \\
\hline Moderate & 33.3 \\
\hline Severe & 24.7 \\
\hline \multicolumn{2}{|l|}{ Type of Operation (\%) } \\
\hline Lumpectomy & 47 \\
\hline Total mastectomy & 53 \\
\hline \multicolumn{2}{|l|}{ Treatments (\%) } \\
\hline $\mathrm{ET}+\mathrm{CT}+\mathrm{RT}$ & 41.98 \\
\hline $\mathrm{CT}+\mathrm{RT}$ & 44.44 \\
\hline $\mathrm{RT}$ & 13.58 \\
\hline Lymph nodes removed (number) $(X \pm S D)$ & $15.94 \pm 8.36$ \\
\hline \multicolumn{2}{|l|}{ History of recurrent lymphangitis (\%) } \\
\hline Yes & 24.7 \\
\hline No & 75.3 \\
\hline Duration of lymphedema (months) $(X \pm S D)$ & $23.12 \pm 30.88$ \\
\hline
\end{tabular}

which gives the item distribution as in the original form of the UL-27 quality of life questionnaire. Questions between 16 and 22 give the psychological score and questions between 23-27 give the social score $\left(x^{2}=463.20\right)(p=0.000)$ (Table 4, Figure 1). Whether the relationship between the variables-assumed absence model that the difference Comperative Fit Index (CFI) according to close to the minimum (0.97) and Incremental Fit Index (IFI) based on "acceptable harmony" (0.97) was detected. Goodness of Fit Index measured the sample covariance matrix of the model (GFI), what is viewed as "acceptable harmony" was determined to be in the group (0.96). With the ULL-27, scoring a minimum of 0 (27) and a maximum of 100 (135) points formula used to be; (total score - minscore $) /($ max score - min score $) \times 100$

Accordingly, 81 individuals participated in the study and the ULL-27 global score for quality of life was found to be $42.54 \pm 19.71$ (Table 5). ULL-27 quality of life questionnaire of 
TABLE 2 | ULL-27 quality of life questionnaire of physical, psychological, social, and global measures of reliability test.

\begin{tabular}{lll}
\hline & Cronbach's alpha & Number of questions \\
\hline Physical Score & 0.90 & 15 \\
Psychological Score & 0.87 & 7 \\
Social Score & 0.75 & 5 \\
Global Score & 0.93 & 27
\end{tabular}

TABLE 3 | Reliability of each question in ULL-27.

\begin{tabular}{|c|c|c|c|}
\hline & Mean \pm SD & $\alpha$ & $r$ \\
\hline Difficulties grasping high objects & $3.17 \pm 1.31$ & 0.90 & 0.47 \\
\hline Difficulties maintaining certain positions & $3.07 \pm 1.33$ & 0.90 & 0.46 \\
\hline Arm feels heavy & $3.30 \pm 1.38$ & 0.89 & 0.69 \\
\hline Arm feels swollen & $3.54 \pm 1.30$ & 0.90 & 0.57 \\
\hline Difficulties getting dressed & $2.72 \pm 1.32$ & 0.89 & 0.74 \\
\hline Having trouble getting to sleep & $2.74 \pm 1.38$ & 0.90 & 0.45 \\
\hline Having trouble sleeping & $2.81 \pm 1.33$ & 0.90 & 0.50 \\
\hline Difficulties grasping objects & $2.75 \pm 1.26$ & 0.89 & 0.68 \\
\hline Difficulties holding objects & $2.96 \pm 1.35$ & 0.90 & 0.64 \\
\hline Difficulties walking heavy arm & $2.53 \pm 1.33$ & 0.89 & 0.77 \\
\hline Difficulties washing & $2.32 \pm 1.30$ & 0.89 & 0.73 \\
\hline Difficulties taking public transport & $2.49 \pm 1.34$ & 0.89 & 0.68 \\
\hline Tingling, burning feelings & $2.67 \pm 1.36$ & 0.90 & 0.43 \\
\hline Feelings of swollen, hard, tense skin & $3.15 \pm 1.33$ & 0.90 & 0.53 \\
\hline Difficulties in working relationship and tasks & $2.75 \pm 1.19$ & 0.90 & 0.60 \\
\hline Feeling sad & $2.61 \pm 1.25$ & 0.73 & 0.73 \\
\hline Feeling discouraged & $2.41 \pm 1.25$ & 0.87 & 0.87 \\
\hline Feeling lack of self-confidence & $2.45 \pm 1.27$ & 0.67 & 0.67 \\
\hline Feeling distressed & $2.79 \pm 1.22$ & 0.81 & 0.81 \\
\hline Feeling well in oneself & $2.82 \pm 1.14$ & 0.26 & 0.26 \\
\hline Feeling a wish to be angry & $2.50 \pm 1.25$ & 0.54 & 0.54 \\
\hline Having confidence in the future & $2.61 \pm 1.30$ & 0.74 & 0.74 \\
\hline $\begin{array}{l}\text { Difficulties taking advantage of good weather, in life } \\
\text { outside the house }\end{array}$ & $2.36 \pm 1.31$ & 0.55 & 0.55 \\
\hline $\begin{array}{l}\text { Difficulty with personal projects holidays and } \\
\text { hobbies }\end{array}$ & $2.89 \pm 1.32$ & 0.60 & 0.60 \\
\hline Difficulties in emotional life with spouse or partner & $2.33 \pm 1.11$ & 0.53 & 0.53 \\
\hline Difficulty in social life & $2.63 \pm 1.13$ & 0.55 & 0.55 \\
\hline Fearful of looking in a mirror & $1.52 \pm 0.838$ & 0.34 & 0.34 \\
\hline
\end{tabular}

the Kolmogorov-Smirnov and Shapiro-Wilk test was performed to examine whether they fit a normal distribution. The test does not conform to a normal distribution $(p<0.05)$. ULL27 questionnaire of physical, psychological, social, and global relationship between the score and the questions were analyzed with Pearson's correlation coefficient. It was found to be statistically significant in itself $(p<0.01)(p<0.05)$. With the Turkish version of ULL-27 quality of life questionnaire, a parallel score was found within the scope of EORTC-QLQ-C30 and BR23 related validity. The correlation between the vertex of all cases of this survey were analyzed by Spearman correlation coefficient. Accordingly, the global score of the ULL-27 questionnaire and
TABLE 4 | ULL-27 Quality of Life questionnaire indices of confirmatory factor analysis.

\begin{tabular}{lllll}
\hline Index & RMSEA & CFI & IFI & GFI \\
\hline ULL-27 Life Quality Questionnaire & 0.074 & 0.97 & 0.97 & 0.96 \\
\hline
\end{tabular}

RMSEA Index (Root Mean Square Error of Approximation), CFI (Comperative Fit Index) and IFI (Incremental Fit Index).

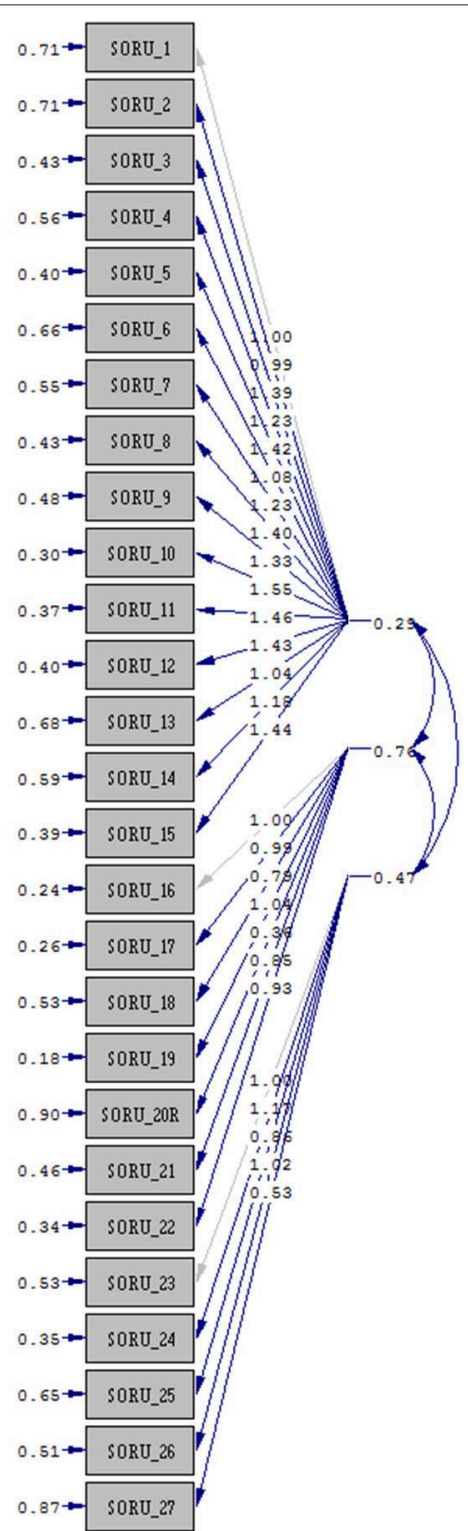

Chi-Square $=463.20, d f=321, \quad P-v a l u e=0.00000, \quad$ RMSEA $=0.074$

FIGURE 1 | Path diagram.

the correlation coefficient between BR23 and C30 and the scores of the scale were found to be significantly similar $(p<0.05)$ (Table 5). A statistically significant difference was found between the psychological items of the ULL-27 questionnaire between 
TABLE 5 | Correlations between ULL-27 and EORT QLQ C30; BR-23 parameters.

Physical score Psychological Social score Global score $\begin{array}{llll}(46.64 \pm 21.90) & \text { score } & (33.64 \pm 20.52) & (42.54 \pm 19.71)\end{array}$

$(40.12 \pm 23.65)$

\begin{tabular}{|c|c|c|c|c|}
\hline QL2 & -0.208 & $-0.472^{\star \star}$ & $-0.324^{\star \star}$ & $-0.337^{\star *}$ \\
\hline$(60.79 \pm 18.93)$ & 0.062 & 0.000 & 0.003 & 0.002 \\
\hline PF2 & $-0.564^{\star \star}$ & $-0.333^{\star \star}$ & $-0.459^{\star *}$ & $-0.546^{\star *}$ \\
\hline$(62.88 \pm 21.51)$ & 0.000 & 0.002 & 0.000 & 0.000 \\
\hline RF2 & $-0.410^{\star \star}$ & $-0.349^{\star \star}$ & $-0.449^{\star \star}$ & $-0.437^{\star *}$ \\
\hline$(63.87 \pm 31.94)$ & 0.000 & 0.001 & 0.000 & 0.000 \\
\hline EF & -0.177 & $-0.526^{\star \star}$ & $-0.362^{\star \star}$ & $-0.328^{* *}$ \\
\hline$(70.23 \pm 24.88)$ & 0.115 & 0.000 & 0.001 & 0.003 \\
\hline CF & -0.101 & $-0.323^{\star \star}$ & $-0.269^{\star}$ & -0.204 \\
\hline$(69.95 \pm 24.91)$ & 0.372 & 0.003 & 0.015 & 0.068 \\
\hline SF & -0.151 & $-0.266^{\star}$ & $-0.297^{\star *}$ & $-0.221^{\star}$ \\
\hline$(75.71 \pm 26.88)$ & 0.178 & 0.016 & 0.007 & 0.047 \\
\hline FA & $0.362^{\star \star}$ & $0.356^{\star *}$ & $0.421^{\star *}$ & $0.417^{\star \star}$ \\
\hline$(44.57 \pm 26.43)$ & 0.001 & 0.001 & 0.000 & 0.000 \\
\hline NV & $0.347^{\star \star}$ & $0.364^{\star \star}$ & $0.406^{\star *}$ & $0.369^{\star *}$ \\
\hline$(12.75 \pm 24.33)$ & 0.001 & 0.001 & 0.000 & 0.000 \\
\hline PA & $0.450^{\star \star}$ & $0.417^{\star \star}$ & $0.519^{\star *}$ & $0.503^{\star \star}$ \\
\hline$(40.32 \pm 28.11)$ & 0.000 & 0.000 & 0.000 & 0.000 \\
\hline DY & $0.384^{\star \star}$ & $0.297^{\star *}$ & $0.343^{\star \star}$ & $0.403^{\star \star}$ \\
\hline$(23.24 \pm 29.77)$ & 0.000 & 0.007 & 0.002 & 0.000 \\
\hline SL & $0.398^{\star \star}$ & $0.465^{\star *}$ & $0.488^{\star *}$ & $0.467^{\star \star}$ \\
\hline$(37.72 \pm 33.58)$ & 0.000 & 0.000 & 0.000 & 0.000 \\
\hline AP & $0.266^{*}$ & $0.402^{\star *}$ & $0.379^{* \star}$ & $0.355^{\star \star}$ \\
\hline$(8.64 \pm 18.08)$ & 0.016 & 0.000 & 0.000 & 0.001 \\
\hline $\mathrm{CO}$ & 0.081 & $0.244^{*}$ & 0.170 & 0.149 \\
\hline$(24.48 \pm 31.07)$ & 0.474 & 0.028 & 0.130 & 0.186 \\
\hline DI & 0.147 & 0.212 & $0.221^{*}$ & 0.207 \\
\hline$(11.52 \pm 25.90)$ & 0.189 & 0.057 & 0.047 & 0.064 \\
\hline $\mathrm{FI}$ & 0.122 & $0.273^{*}$ & 0.161 & 0.177 \\
\hline$(22.83 \pm 29.39)$ & 0.277 & 0.014 & 0.152 & 0.113 \\
\hline BRBI & -0.183 & $-0.321^{\star \star}$ & $-0.239^{\star}$ & $-0.248^{\star}$ \\
\hline$(71.19 \pm 25.10)$ & 0.102 & 0.004 & 0.032 & 0.025 \\
\hline BRSEF & 0.065 & 0.019 & 0.081 & 0.068 \\
\hline$(81.89 \pm 24.60)$ & 0.566 & 0.866 & 0.472 & 0.545 \\
\hline BRSEE & 0.045 & 0.015 & 0.088 & 0.049 \\
\hline$(78.59 \pm 30.41)$ & 0.688 & 0.891 & 0.433 & 0.662 \\
\hline BRFU & $-0.241^{\star}$ & $-0.423^{\star *}$ & $-0.351^{* *}$ & $-0.343^{\star *}$ \\
\hline$(48.13 \pm 30.27)$ & 0.030 & 0.000 & 0.001 & 0.002 \\
\hline BRST & $0.268^{*}$ & $0.381^{* *}$ & $0.389^{* *}$ & $0.348^{* *}$ \\
\hline$(28.59 \pm 18.12)$ & 0.015 & 0.000 & 0.000 & 0.001 \\
\hline BRBS & $0.228^{*}$ & 0.202 & 0.215 & $0.225^{\star}$ \\
\hline$(29.82 \pm 24.11)$ & 0.041 & 0.071 & 0.054 & 0.044 \\
\hline BRAS & $0.606^{\star \star}$ & $0.313^{\star \star}$ & $0.504^{\star \star}$ & $0.562^{\star \star}$ \\
\hline$(49.84 \pm 25.52)$ & 0.000 & 0.004 & 0.000 & 0.000 \\
\hline $\mathrm{BRHL}$ & 0.176 & 0.064 & 0.012 & 0.122 \\
\hline$(15.21 \pm 28.87)$ & 0.115 & 0.569 & 0.918 & 0.278 \\
\hline
\end{tabular}

${ }^{* *} p<0.001,{ }^{*} p<0.005$.

physical-PF2, role-RF2, cognitive-CF, emotional-EF, social functioning-SF, fatigue$F A$, nausea \& vomiting-NV, pain-FA, dyspnea-DY, insomnia-SL, appetite loss$A P$, constipation-CO, diarrhea-DI, financial difficulties-FI, Body Image-BRBI, Sexual Functioning-BRSEF, Sexual Enjoyment-BRSEE, Future Perspective-BRFU, systemic therapy side effects -BRST, breast symptoms -BRBS, arm symptoms -BRAS, upset by hair loss-BRHL.

The values in the table show that the ones with negative sign are negative meaningful and those without sign have positive meaning.

diarrhea, sexual function, sexual pleasure, breast symptoms, and sadness that caused hair loss $(p<0.05)$. Shortly, we found that symptom scores worsened as the severity of lymphedema increased. Accordingly, we saw that the quality of life decreased (Graph 1). We have demonstrated that the Turkish version of the ULL-27 quality of life questionnaire we evaluated was a valid and reliable test battery for the use of patients to evaluate the condition.

\section{DISCUSSION}

After breast cancer treatment approaches, people face several problems. These problems affect the quality of life of the individual. Lymphedema is one of these problems. Therefore, it is important to measure the degree to which the quality of life in people with BCRL is affected. In our study, we assessed reliability and validity of the Turkish version of ULL-27 in the upper limb lymphedema. The ULL-27 was found to be a valid and reliable measure in Turkish patients with BCRL. Previous studies stated that upper limb lymphedema effects patient's lives in different ways and there were many symptoms which were specific like heaviness and swollen limbs. The SF36, EORTC QLQ C-30, and BR-23 are the most preferable scales for patients having upper limb lymphedema. Lymphedema specific questionnaires such as Lymph ICF, LyQLI, and LYMQOL have started to be used to assess patients by professionals (21-23). EORT QLQ C-30 and BR-23 are the most frequently used parameters to assess the disease-specific quality of life in people who have had breast cancer in Turkey. So, EORT QLQ C-30, BR-23, and ULL-27 was the main assessment parameters in this study. The EORT QLQ C-30 involved all breast cancer symptoms, and only four out of nine specific questions were about arm symptoms $(18,24,25)$. Its manual scoring take long time, whereas ULL-27 is only about upper limb lymphedema symptoms and quickly calculates the score. Pusic et al. showed that according to COSMIN criteria the ULL27 was the only scale that could be used with patients that left no doubt on the results (18). ULL-27 physical, psychological, and social scores of Cronbach's alpha values were supported by Launois and Viehoff. Launois et al. were calculated in the same way (15). Similarly, Viehoff et al. reported that the Dutch version of the questionnaire was a valid and reliable study, Cronbach's alpha values were found to be close (26). Our values showed parallel values. In this study we found physical, psychological, and social Cronbach's alpha values that were relatively high. Global score Croncbach's alpha was found by calculating the high reliability of the questionnaire. ULL-27 and EORT QLQ C-30, BR-23 sub parameters were found to be highly correlated. In order to be able to compare our results with those of the original questionnaire, the tests were performed in a similar attitude. A factor analysis was done with RMSEA, Comparative Fit Index (CFI), and Incremental Fit Index (IFI). Goodness of Fit Index (GFI) was evaluated for covariance and we found that ULL-27 questionnaire is suitable for Turkish BCRL patients. Structural equation of the questionnaire showed high adaptation.

Physical scores of individuals (ULL-27) was found to be an average. We considered this a score that increases an individual's 


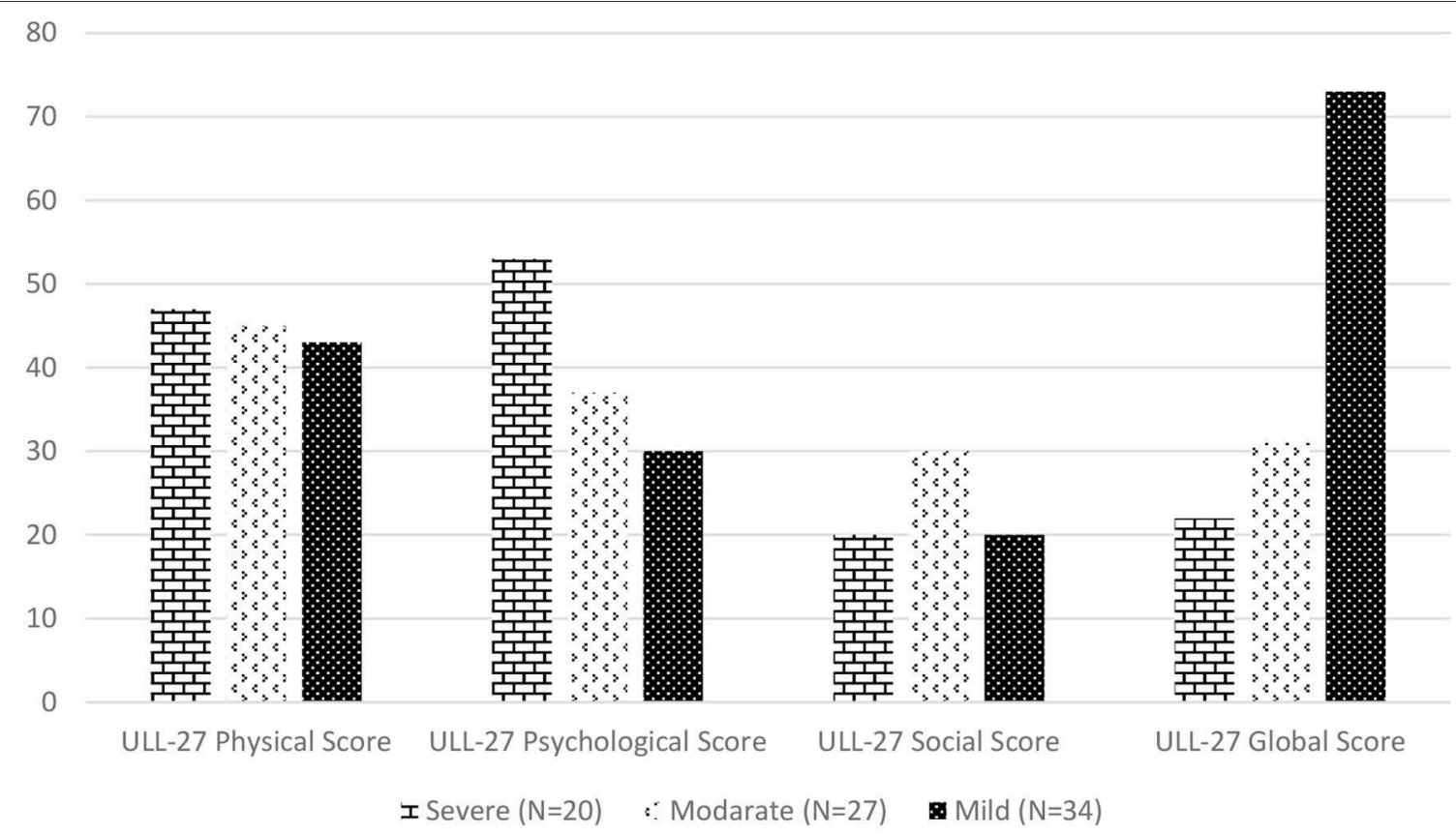

GRAPH 1 | According to lymphedema severity quality of life scores of ULL-27.

quality of life deteriorated. The EORTC C30 is consistent with the scores of the quality of life, physical function, role function, emotional function, cognitive function and social function parameters and the physical score of the ULL 27 quality of life questionnaire. The higher the ULL-27 quality of life score, the higher the other parameters. According to the analysis of ULL-27 in individuals with high physical score points, we saw a low score of the role and function scale in EORT C-30. We have seen that pain, weakness, nausea-vomiting, insomnia, dyspnea, anorexia, constipation, diarrhea, and financial parameters decrease the quality of life. We found that when individuals' ULL-27 physical score increased, fatigue, nausea, vomiting, pain, shortness of breath, insomnia, and loss of appetite worsened. We have also seen that high ULL-27 physical score has a negative impact on BR-23 body image, sexual function, sexual satisfaction, and future opinion parameters. Likewise, we found that patients with the highest physical score had higher breast and arm symptoms.

Psychological and social dimensions also affect individuals' quality of life. The high points of sexual function and sexual pleasure have a negative impact on an individual's quality of life. Our study is high in these two parameters. We observed that the psychological score of ULL-27 worsened as the hair loss symptom score increased. One of the side effects of chemotherapy is hair loss. Although time has passed, this causes us to think that the effect of this situation continues. In this study, we found that the physical and cosmetic effects of treatments generally affect the social and psychological state of those with BCRL.

One study limitation was that there were not enough participants. This lack of participants might have affected the results of our study. One strength of our work was that all patients were women. Lymphedema after breast cancer in women is very high so we think that our results are close to the general population.

In conclusion, the ULL-27 questionnaire seems to be a reliable and valid scale for assessing the quality of life in Turkish upper limb lymphedema patients. It is available for use in clinical practice and research.

\section{DATA AVAILABILITY STATEMENT}

The raw data supporting the conclusions of this article will be made available by the authors, without undue reservation.

\section{ETHICS STATEMENT}

This article does not contain any studies involving animals performed by any of the authors. All procedures performed in studies involving human participants were in accordance with the ethical standards of the institutional research committee and with the 1964 Helsinki Declaration and its later amendments or comparable ethical standards. Informed consent was obtained from all individual participants involved in the study.

\section{AUTHOR'S NOTE}

The ULL27 was developed by Professor Robert Launois with an educational grant from REES France. Any person who wishes to use the questionnaire should contact Professor Robert Launois (reesfrance@wanadoo.fr). 


\section{AUTHOR CONTRIBUTIONS}

AK and DK conceived of the presented idea. TY developed the theory and performed the computations. AK and DK

\section{REFERENCES}

1. Ghoncheh M, Pournamdar Z, Salehiniya H. Incidence and mortality and epidemiology of breast cancer in the world. Asian Pacific J Cancer Prev. (2016) 17:43-6. doi: 10.7314/APJCP.2016.17.S3.43

2. Ozmen V, Ozmen T, Dogru V. Breast cancer in turkey; an analysis of 20.000 patients with breast cancer. Eur J Breast Heal. (2019) 15:141-6. doi: 10.5152/ejbh.2019.4890

3. Rivera-Franco MM, Leon-Rodriguez E. Delays in breast cancer detection and treatment in developing countries. Breast Cancer Basic Clin Res. (2018) 12:117822341775267. doi: 10.1177/1178223417752677

4. Narod SA, Iqbal J, Miller AB. Why have breast cancer mortality rates declined? J Cancer Policy. (2015) 5:8-17. doi: 10.1016/j.jcpo.2015.03.002

5. DiSipio T, Rye $S$, Newman B, Hayes S. Incidence of unilateral arm lymphoedema after breast cancer: A systematic review and meta-analysis. Lancet Oncol. (2013) 14:500-15. doi: 10.1016/S1470-2045(13)70076-7

6. Soojin Ahn Elisa Port R, Mount Sinai Medical Center. Lymphedema precautions: time to abandon old practices? J Clin Oncol. (2016) 34:691. doi: 10.1200/JCO.2015.64.9574

7. Huang T-W, Tseng S-H, Lin CC, Bai CH, Chen CS, Hung CS, et al. Effects of manual lymphatic drainage on breast cancer-related lymphedema: a systematic review and meta-analysis of randomized controlled trials. World J Surg Oncol. (2013) 11:15. doi: 10.1186/1477-781911-15

8. Tsai RJ, Dennis LK, Lynch CF, Snetselaar LG, Zamba GK, ScottConner C. The risk of developing arm lymphedema among breast cancer survivors: A meta-analysis of treatment factors. Ann Surg Oncol. (2009) 16:1959-72. doi: 10.1245/s10434-009-0452-2

9. Warren LEG, Miller CL, Horick N, Skolny MN, Jammallo LS, Sadek BT, et al. The impact of radiation therapy on the risk of lymphedema after treatment for breast cancer: A prospective cohort study. Int J Radiat Oncol Biol Phys. (2014) 88:565-71. doi: 10.1016/j.ijrobp.2013.11.232

10. Shaitelman SF. Radiation therapy targets and the risk of breast cancerrelated lymphedema: a systematic review and network meta-analysis. Breast Cancer Res Treat. (2016) 162:201-15. doi: 10.1007/s10549-0164089-0

11. Schmitz KH, Ahmed RL, Troxel A, Cheville A, Smith R, Lewis-Grant L, Bryan CJ, et al. Weight lifting in women with breast-cancer-related lymphedema. N Engl J Med. (2009) 361:664-73. doi: 10.1056/NEJMoa08 10118

12. Norman SA, Localio AR, Potashnik SL, Cheville A, Smith R, LewisGrant L, et al. Lymphedema in breast cancer survivors: incidence, degree, time course, treatment, and symptoms. J Clin Oncol. (2009) 361:664-73. doi: 10.1200/JCO.2008.17.9291

13. Schmitz KH, Troxel AB, Cheville A, Grant LL, Bryan CJ, Gross CR, et al. Physical activity and lymphedema (the PAL trial): Assessing the safety of progressive strength training in breast cancer survivors. Contemp Clin Trials. (2009) 30:233-45. doi: 10.1016/j.cct.2009.01.001

14. Wanchai A, Armer JM, Stewart BR, Lasinski BB. Breast cancer-related lymphedema: A literature review for clinical practice. Int J Nurs Sci. (2016) 3:207-9. doi: 10.1016/j.ijnss.2016.04.006 verified the analytical methods. DK encouraged AK to investigate (a specific aspect) and supervised the findings of this work. All authors discussed the results and contributed to the final manuscript.

15. Launois R, Mègnigbêto AC, Pocquet K, Alliot F. A specific quality of life scale in upper limb lymphedema : the ULL-27 questionnaire. Genoa Lymphol. (2001) 35:1-760. doi: 10.1016/S1098-3015(11)71503-0

16. Warren AG, Brorson H, Borud LJ, Slavin SA. Lymphedema: A comprehensive review. Ann Plast Surg. (2007) 59:46472. doi: 10.1097/01.sap.0000257149.42922.7e

17. Aaronson NK, Ahmedzai S, Bergman B, Bullinger M, Cull A, Duez NJ, et al. The European Organization for Research and Treatment of Cancer QLQ-C30: a quality-of-life instrument for use in international clinical trials in oncology. J Natl Cancer Inst. (1993) 85:365-76. doi: 10.1093/jnci/85.5.365

18. Demirci S, Eser E, Ozsaran Z, Tankisi D, Aras AB, Ozaydemir G, et al. Validation of the Turkish versions of EORTC QLQ-C30 and BR23 modules in breast cancer patients. Asian Pac J Cancer Prev. (2011) 12:1283-7.

19. Bombardier C, Guillemin F, Ferraz M. Recommendations for the crosscultural adaptation of health status measures. Am Acad Orthop Surg. (1998) 1-27.

20. Beaton DE, Bombardier C, Guillemin F, Ferraz MB. Guidelines for the process of cross-cultural adaptation of self-report measures. Spine. (2000) 25:318691. doi: 10.1097/00007632-200012150-00014

21. Devoogdt N, Van Kampen M, Geraerts I, Coremans T, Christiaens MR Lymphoedema functioning, disability and health questionnaire. (Lymph-ICF) reliability and validity. Phys Ther. (2011) 91:944-57. doi: 10.2522/ptj.20100087

22. Klernäs P, Johnsson A, Horstmann V, Kristjanson LJ, Johansson K. Lymphedema quality of life inventory. (LyQLI). -development and investigation of validity and reliability. Qual Life Res. (2015) 24:427-39. doi: 10.1007/s11136-014-0783-8

23. Keeley V, Crooks S, Locke J, Veigas D, Riches K, Hilliam R. A quality of life measure for limb lymphoedema (LYMQOL). JLymphoedema. (2010) 5:26-37.

24. Kim EJ, Ko SK, Kang HY. Mapping the cancer-specific EORTC QLQ-C30 and EORTC QLQ-BR23 to the generic EQ-5D in metastatic breast cancer patients. Qual Life Res. (2012) 21:1193-203. doi: 10.1007/s11136-011-0037-y

25. Leng T, Ching S, Idris D, Loh SY, Seow GC, Chia YY, et al. Validation of EORTC QLQ-C30 and QLQ-BR23 questionnaires in the measurement of quality of life of breast cancer patients in Singapore. Asia-Pacific J Oncol Nurs. (2014) 1:22-32. doi: 10.4103/2347-5625.135817

26. Viehoff PB, van Genderen FR, Wittink H. Upper limb lymphedema 27. (ULL27). : dutch translation and validation of an illness-specific healthrelated quality of life questionnaire for patients with upper limb lymphedema. Lymphology. (2008) 41:131-8.

Conflict of Interest: The authors declare that the research was conducted in the absence of any commercial or financial relationships that could be construed as a potential conflict of interest.

Copyright (c) 2020 Kayali Vatansever, Yavuzşen and Karadibak. This is an openaccess article distributed under the terms of the Creative Commons Attribution License (CC BY). The use, distribution or reproduction in other forums is permitted, provided the original author(s) and the copyright owner(s) are credited and that the original publication in this journal is cited, in accordance with accepted academic practice. No use, distribution or reproduction is permitted which does not comply with these terms. 